\title{
Effect of Resveratrol on Hematological and Biochemical Alterations in Rats Exposed to Fluoride
}

\author{
Nurgül Atmaca, ${ }^{1}$ Ebru Yıldırım, ${ }^{2}$ Bayram Güner, ${ }^{3}$ Ruhi Kabakçı, ${ }^{1}$ and Fatih Sultan Bilmen ${ }^{1}$ \\ ${ }^{1}$ Department of Physiology, Faculty of Veterinary Medicine, Kirikkale University, 71451 Kirikkale, Turkey \\ ${ }^{2}$ Department of Pharmacology and Toxicology, Faculty of Veterinary Medicine, Kirikkale University, 71451 Kirikkale, Turkey \\ ${ }^{3}$ Department of Biochemistry, Faculty of Veterinary Medicine, Kirikkale University, 71451 Kirikkale, Turkey
}

Correspondence should be addressed to Nurgül Atmaca; nurgulzengin@yahoo.com

Received 26 February 2014; Revised 16 May 2014; Accepted 24 May 2014; Published 5 June 2014

Academic Editor: Francesco Dondero

Copyright (C) 2014 Nurgül Atmaca et al. This is an open access article distributed under the Creative Commons Attribution License, which permits unrestricted use, distribution, and reproduction in any medium, provided the original work is properly cited.

\begin{abstract}
We investigated the protective effects of resveratrol on hematological and biochemical changes induced by fluoride in rats. A total of 28 rats were divided into 4 groups: control, resveratrol, fluoride, and fluoride/resveratrol ( $n=7$ each), for a total of 21 days of treatment. Blood samples were taken and hematological and biochemical parameters were measured. Compared to the control group, the fluoride-treated group showed significant differences in several hematological parameters, including decreases in WBC, RBC, and PLT counts and neutrophil ratio. The group that received resveratrol alone showed a decrease in WBC count compared to the control group. Furthermore, in comparison to the control group, the fluoride group showed significantly increased ALT enzyme activity and decreased inorganic phosphorus level. The hematological and biochemical parameters in the fluoride + resveratrol treated group were similar to control group. In the fluoride + resveratrol group, resveratrol restored the changes observed following fluoride treatment, including decreased counts of WBC, RBC, and PLT, decreased neutrophil ratio and inorganic phosphorus levels, and elevated ALT enzyme activity. The present study showed that fluoride caused adverse effects in rats and that resveratrol reduced hematological and biochemical alterations produced by fluoride exposure.
\end{abstract}

\section{Introduction}

Fluoride is an essential element [1] but one that can cause serious health problems when drinking water contains fluoride at a concentration greater than $1 \mathrm{ppm}$ or in the regions where a large amount of fluoride is released due to the burning of fluoride-loaded coal $[2,3]$. Fluoride causes adverse effects in soft tissues such as blood, brain, and liver [4] by passing through the cell membrane [5]. Fluoride accumulates in bone tissues, where it can negatively affect hematopoiesis occurring in bone marrow [6]. In addition, as a site of very active metabolism, the liver is especially susceptible to fluoride toxicity [7]. However, it has been reported that changes due to fluoride exposure occur earlier in blood compared to other tissues and organs [8]. Previous studies revealed that fluoride had unfavorable effects on hematological and biochemical parameters $[9,10]$ in rats $[11,12]$, mice $[13-15]$, sheep [16], rabbits $[17,18]$, dogs [19], camels [20], and humans [8, 21].
It has been reported that antioxidants in the diet, such as black tea extract [22], a combination of vitamin $\mathrm{E}$ with methionine and 1-carnosine [12], Panax ginseng [14], and pineal proteins and melatonin [23], reduce the harmful effects of fluoride. Resveratrol (trans-3,5,4'-trihydroxystilbene) is a phytoalexin that is found in foods including grapes, plums, cranberries, and peanuts [24]. In addition, its antioxidant efficacy has been demonstrated in traumatic brain injury $[25,26]$, methotrexate-induced liver toxicity $[27,28]$, cisplatin- [29] and gentamicin-induced nephrotoxicity [30], and doxorubicin-induced cardiotoxicity [31]. However, no previous study exists on the potential of resveratrol to alleviate or eliminate adverse effects produced by fluoride exposure in rats.

The present study investigated the protective effects of resveratrol, a potent antioxidant, on fluoride-induced alterations in hematological and biochemical parameters of the blood, which is a target tissue for fluoride toxicity. 
TABLE 1: Hematological parameters in control and experimental groups.

\begin{tabular}{|c|c|c|c|c|c|}
\hline & Control & Resveratrol & Fluoride & Fluoride + resveratrol & $P$ values \\
\hline $\mathrm{WBC}\left(10^{3} / \mathrm{mm}^{3}\right)$ & $7.99^{\mathrm{a}}$ & $4.22^{\mathrm{bc}}$ & $4.85^{\mathrm{c}}$ & $8.15^{\mathrm{a}}$ & 0.002 \\
\hline Lymphocyte (\%) & 64.20 & 61.80 & 71.90 & 53.50 & NS \\
\hline Neutrophil (\%) & $32.60^{\mathrm{a}}$ & $32.30^{\mathrm{a}}$ & $22.80^{\mathrm{b}}$ & $39.10^{\mathrm{a}}$ & 0.029 \\
\hline $\operatorname{RBC}\left(10^{6} / \mathrm{mm}^{3}\right)$ & $7.99^{\mathrm{a}}$ & $8.71^{\mathrm{a}}$ & $7.46^{\mathrm{b}}$ & $8.05^{\mathrm{a}}$ & 0.022 \\
\hline HGB (gr/dL) & 13.70 & 13.10 & 13.00 & 12.00 & NS \\
\hline $\operatorname{HCT}(\%)$ & 38.95 & 35.96 & 38.87 & 34.59 & NS \\
\hline MCV (fL) & 49.00 & 45.00 & 52.00 & 43.00 & NS \\
\hline $\mathrm{MCH}(\mathrm{pg})$ & 17.30 & 15.40 & 17.10 & 14.90 & NS \\
\hline $\mathrm{MCHC}(\mathrm{g} / \mathrm{dL})$ & 34.00 & 34.70 & 32.90 & 34.00 & NS \\
\hline $\operatorname{PLT}\left(10^{3} / \mathrm{mm}^{3}\right)$ & $758^{\mathrm{ac}}$ & $999^{\mathrm{a}}$ & $403^{\mathrm{b}}$ & $699^{c}$ & 0.007 \\
\hline
\end{tabular}

Results were expressed as median. Data having different superscript letter within the same row were statistically different from each other. NS: not significant.

\section{Materials and Methods}

2.1. Drugs and Reagents. Sodium fluoride (NaF) was purchased from Merck. trans-Resveratrol was obtained from Cayman Chemical Company. All other chemicals were obtained from Merck Chemical, Inc. (Darmstadt, Germany).

2.2. Animals and Treatment. Experiments were carried out in male Wistar albino rats weighing 180-200 g, which were fed standard chow diet and water available ad libitum. The animals were housed in plastic cages, under a $12 \mathrm{~h}$ light/dark cycle (lights on from 08:00 a.m.) at a constant temperature of $25 \pm 2^{\circ} \mathrm{C}$ with $42 \pm 5 \%$ relative humidity. The study protocol was in accordance with the guidelines for animal research and it was approved by the Ethical Committee of the Kirıkkale University (10/155). Twenty-eight rats were randomly divided into four groups of seven animals each. Experimental groups were designed as follows: control group received distilled water; resveratrol group received daily resveratrol $(12.5 \mathrm{mg} / \mathrm{kg}$ b.w.) intraperitoneally (i.p.) and distilled water fluoride group received daily $100 \mathrm{mg} / \mathrm{L}$ fluoride in drinking water; fluoride + resveratrol group received daily $100 \mathrm{mg} / \mathrm{L}$ fluoride in drinking water plus resveratrol (12.5 mg/kg b.w., i.p.) for 21 days. The dose and route of fluoride were chosen from previous studies $[32,33]$. The selected dose and route for resveratrol used in the study were determined according to Mokni et al. [34].

2.3. Sample Collection. At the end of the 21st day, blood samples were collected into heparinised tubes by cardiac puncture from all animals, under light ether anesthesia.

2.4. Hematological Assay. White blood cells (WBC), lymphocyte and neutrophil ratio, red blood cells (RBC), hematocrit (Hct), hemoglobin $(\mathrm{Hb})$, mean cell volume (MCV), mean cell hemoglobin $(\mathrm{MCH})$, mean cell hemoglobin concentration (MCHC), and platelet count (PLT) were measured on Hematology Analyzer (Abacus Junior Vet 5, Austria).

2.5. Biochemical Assay. Cholesterol, albumin, calcium (Ca), and inorganic phosphate $(\mathrm{Pi})$ levels were determined using Diasis (Germany) kits and aspartate aminotransferase (AST) (EC 2.6.1.1), alanine aminotransferase (ALT) (EC 2.6.1.2), and alkaline phosphatase (ALP) (EC 3.1.3.1) activities were measured using Biolabo (France) kits by spectrophotometer (Shimadzu, UV 1700, Shimadzu, Japan) using commercial assay kits according to the manufacturer's directions.

2.6. Statistical Analysis. Data processing was performed with the SPSS 15.0 (SPSS, Inc., Chicago, IL, USA). The normality of all data was assessed by Spreads versus Level with Levene Test. The hematological parameters were distributed nonparametrically and therefore tested using Kruskal-Wallis test followed by the Mann-Whitney $U$ test to determine which of the four groups differed from each other. Biochemical parameters were analysed by one-way analysis of variance (ANOVA). When the $F$ values were significant, Duncan's Multiple Range Test was performed. $P$ values less than 0.05 were considered significant for all statistical calculations.

\section{Results}

As shown in Table 1, the data showed that treatment with fluoride caused a significant decrease in WBC, RBC, and PLT counts and neutrophil ratio in fluoride treated group as compared to control group. The hematological parameters in the fluoride + resveratrol treated group were similar to control group. In the fluoride plus resveratrol group, resveratrol alleviated the adverse effects on WBC, RBC, and PLT counts and neutrophil ratio caused by fluoride.

The biochemical parameters of the experimental groups were presented in Table 2. Enzyme activity of ALT was statistically increased in fluoride group as compared to control group. The plasma inorganic phosphorus level was significantly decreased in fluoride group as compared to control group. The biochemical parameters in the fluoride + resveratrol treated group were similar to control group. In the fluoride plus resveratrol group, resveratrol alleviated the adverse effects on ALT enzyme activity $(P>0.05)$ and inorganic phosphorus levels $(P<0.05)$ by fluoride. Other parameters did not differ in between.

\section{Discussion}

The present study investigated the protective effects of resveratrol on hematological and biochemical changes in 
TABle 2: Plasma biochemical constituents in control and experimental groups.

\begin{tabular}{|c|c|c|c|c|c|}
\hline & Control & Resveratrol & Fluoride & Fluoride + resveratrol & $P$ values \\
\hline$\overline{\operatorname{ALT}}(\mathrm{U} / \mathrm{L})$ & $10.25 \pm 3.72^{\mathrm{b}}$ & $11.86 \pm 2.25^{\mathrm{b}}$ & $33.58 \pm 6.73^{\mathrm{a}}$ & $23.72 \pm 4.76^{\mathrm{ab}}$ & 0.006 \\
\hline $\operatorname{AST}(\mathrm{U} / \mathrm{L})$ & $95.01 \pm 11.91$ & $84.62 \pm 9.86$ & $112.34 \pm 9.95$ & $94.84 \pm 4.72$ & NS \\
\hline $\operatorname{ALP}(\mathrm{U} / \mathrm{L})$ & $399.10 \pm 88.83$ & $290.64 \pm 18.05$ & $385.12 \pm 41.22$ & $338.46 \pm 29.43$ & NS \\
\hline Cholesterol (mg/dL) & $41.81 \pm 3.29$ & $46.79 \pm 5.34$ & $46.27 \pm 2.00$ & $56.72 \pm 3.74$ & NS \\
\hline Albumin (g/dL) & $2.92 \pm 0.16$ & $2.56 \pm 0.20$ & $2.64 \pm 0.20$ & $2.66 \pm 0.21$ & NS \\
\hline $\mathrm{Ca}(\mathrm{mg} / \mathrm{dL})$ & $10.24 \pm 0.67$ & $9.85 \pm 0.71$ & $8.12 \pm 0.44$ & $8.50 \pm 0.64$ & NS \\
\hline $\mathrm{Pi}(\mathrm{mg} / \mathrm{dL})$ & $8.62 \pm 0.32^{\mathrm{a}}$ & $8.79 \pm 0.74^{\mathrm{a}}$ & $4.64 \pm 0.65^{\mathrm{c}}$ & $6.45 \pm 0.31^{\mathrm{b}}$ & 0.000 \\
\hline
\end{tabular}

The data were expressed as mean \pm standard error. Data having different superscript letter within the same row were statistically different from each other. NS: not significant.

rats induced by sodium fluoride. Similar to our studies, others have shown decreases in WBC and PLT counts [35], neutrophil ratio [20], and RBC count $[13,33,36]$ in animals treated with fluoride. Some studies reported that fluoride caused changes in blood parameters such as $\mathrm{Hb}, \mathrm{Hct}, \mathrm{MCV}$, $\mathrm{MCH}$, and $\mathrm{MCHC}[12,37]$, but in this study no statistical differences were observed in these parameters. In the present study, it was observed that fluoride-induced hematological changes were ameliorated in the group that received fluoride and resveratrol. It has been reported that fluoride toxicity causes hematopoietic progenitor cells injury in humans [6] and mice [38]. Decreased WBC, PLT, and neutrophil counts observed in the present study were probably due to harmful effects of fluoride on bone marrow and hematopoietic organs. In the present study, in which no anemia was observed, decreased RBC count may have been associated with a decreased rate of erythrogenesis due to the negative effect of fluoride on erythropoiesis or to shortened life span of erythrocytes and membrane degeneration by means of fluoride causing erythrocytes to change into echinocytes [39]. Unlike Juan et al. [40], who reported that high-dose resveratrol administration did not change hematological parameters in rats, the present study found WBC count to be significantly lower in the group that received resveratrol alone, as compared to the control group. Considering the antiinflammatory characteristic of resveratrol [41], the observed decrease in WBC was expected. Hişmioğulları et al. [42] also reported that $\mathrm{WBC}$ count was decreased in rats given resveratrol. One of the most important findings of this study was that some fluoride-induced hematological changes were improved in the group that received resveratrol with fluoride. These results suggest a beneficial effect of resveratrol treatment against fluoride-induced changes in bone marrow and hematopoietic progenitor cells.

Some biochemical parameters, such as ALT activity, which is correlated with hepatic necrosis in rats [43] and indicates alteration in hepatic functions, were higher in the group that received fluoride as compared to the control group, despite the absence of differences in plasma ALP activity, urea, albumin, calcium, and inorganic phosphorus levels. The present study observed statistically insignificant increases in AST activity in the fluoride-treated group. Fluoride-induced elevations in AST and ALT activity have been reported in rats by Eraslan et al. [32] and in mice by Bouaziz et al. [44].
In contrast to the present study, Xiong et al. [45] reported that AST and ALT activities did not change as a result of exposure to fluoride in children diagnosed with dental fluorosis, whereas Kanbur et al. [10] reported that fluoride decreased ALT activity in mice, while increasing AST activity. Although there was no significant alteration in ALT or AST enzyme activity in the group that received resveratrol with fluoride, as compared to the control group and fluoride group, it was observed that both enzyme activities in this group showed a downward tendency. The liver, which has an active metabolism, is extremely sensitive to fluoride toxicity [46]. The insignificant decrease in AST and ALT enzyme activity in the group that received resveratrol with fluoride suggested that resveratrol had a protective effect on the liver.

An insignificant decrease in calcium level was recorded in the fluoride-treated group in this study. Phosphorus enters the cell as inorganic phosphorus via a secondary active transport mechanism [47]. The $\mathrm{Na}^{+} / \mathrm{K}^{+}$ATPase pump, which is involved in the transport of phosphorus, has been reported to be inhibited by sodium fluoride [48]. Furthermore, Anderson et al. [49] demonstrated that fluoride increased $\mathrm{Na}^{+} / \mathrm{K}^{+}$ ATPase pump activity in osteoblast-like cells. Reduced inorganic phosphorus in the fluoride-treated group can be attributed to the increased activity of the $\mathrm{Na}^{+} / \mathrm{K}^{+}$ATPase pump and the increase of inorganic phosphorus influx into the cell, which caused a decrease in phosphorus in the blood. In this study, the reduced inorganic phosphorus level was ameliorated by resveratrol.

\section{Conclusions}

In conclusion, two remarkable results have emerged from this study. First, fluoride exposure caused changes in hematological and biochemical parameters, which were not in perfect agreement with other studies. These discrepancies are thought to be related to the dose and duration of fluoride exposure, as well as to differences in animal species and individual differences. Second, resveratrol reduced some harmful effects induced by fluoride treatment.

\section{Conflict of Interests}

The authors declare that there is no conflict of interests regarding the publication of this paper. 


\section{References}

[1] C. B. Dissanayake, "The fluoride problem in the groundwater of Sri Lanka-environmental management and health," International Journal of Environmental Studies, vol. 38, no. 2-3, pp. 137156, 1991.

[2] A. K. Susheela, "Fluorosis management programme in India," Current Science, vol. 77, no. 10, pp. 1250-1256, 1999.

[3] E. Zeiger, M. D. Shelby, and K. L. Witt, "Genetic toxicity of fluoride," Environmental and molecular mutagenesis, vol. 21, no. 4, pp. 309-318, 1993.

[4] P. J. Mullenix, P. K. Denbesten, A. Schunior, and W. J. Kernan, "Neurotoxicity of sodium fluoride in rats," Neurotoxicology and Teratology, vol. 17, no. 2, pp. 169-177, 1995.

[5] C. H. Carlson, W. D. Armstrong, and L. Singer, "Distribution and excretion of radiofluoride in the human," Proceedings of the Society for Experimental Biology and Medicine, vol. 104, pp. 235239, 1960.

[6] B. Machaliński, M. Zejmo, I. Stecewicz, A. Machalinska, Z. Machoy, and M. Z. Ratajczak, "The influence of sodium fluoride on the clonogeneclty of human hematopoietic progenitor cells: preliminary report," Fluoride, vol. 33, no. 4, pp. 168-173, 2000.

[7] W. Y. Wang and Y. H. Li, "Environmental epidemiology of fluorine and its effects on health," Soil and Environmental Science, vol. 11, pp. 383-387, 2002.

[8] B. Ravichandran, S. Chattopadhyay, P. K. Gangopadhyay, and H. N. Saiyed, "Evaluation of hematological changes in population exposed to fluoride," Toxicological and Environmental Chemistry, vol. 94, no. 10, pp. 2052-2056, 2012.

[9] V. Paul, P. Ekambaram, and A. R. Jayakumar, "Effects of sodium fluoride on locomotor behavior and a few biochemical parameters in rats," Environmental Toxicology and Pharmacology, vol. 6, no. 3, pp. 187-191, 1998.

[10] M. Kanbur, G. Eraslan, S. Silici, and M. Karabacak, "Effects of sodium fluoride exposure on some biochemical parameters in mice: evaluation of the ameliorative effect of royal jelly applications on these parameters," Food and Chemical Toxicology, vol. 47, no. 6, pp. 1184-1189, 2009.

[11] C. A. Y. B. Priya, K. Anitha, E. Murali Mohan, K. S. Pillai, and P. B. Murthy, “Toxicity of fluoride to diabetic rats," Fluoride, vol. 30, no. 1, pp. 43-50, 1997.

[12] F. E. Agha, M. O. El-Badry, D. A. A. Hassan, and A. Abd Elraouf, "Role of vitamin $\mathrm{E}$ in combination with methionine and Lcarnosine against sodium fluoride-induced hematological, biochemical, DNA damage, histological and immunohistochemical changes in pancreas of albino rats," Life Science Journal, vol. 9, no. 2, pp. 1260-1275, 2012.

[13] K. S. Pillai, A. T. Mathai, and P. B. Deshmukh, "Effect of subacute dosage of fluoride on male mice," Toxicology Letters, vol. 44, no. 1-2, pp. 21-29, 1988.

[14] A. Karadeniz and L. Altintas, "Effects of Panax ginseng on fluoride-induced haematological pattern changes in mice," Fluoride, vol. 41, no. 1, pp. 67-71, 2008.

[15] A. V. B. Rao and S. Vidyunmala, "Cumulative effect of fluoride on hematological indices of mice, Mus Norvegicus albinus," The American-Eurasian Journal of Toxicological Science, vol. 2, no. 2, pp. 93-95, 2010.

[16] S. M. Mohiuddin and M. V. Reddy, "Haematological and biochemical studies on fluoride toxicity in sheep," Indian Veterinary Journal, vol. 66, pp. 1089-1091, 1989.

[17] N. Cetin, A. Bilgili, G. Eraslan, and A. Koyu, “Tavşanlarda flor uygulamasının bazı kan parametreleriüzerine etkisi," Erciyes
University Journal of Health Science, vol. 13, no. 2, pp. 46-50, 2004.

[18] K. Naresh, S. Sushma, S. Manjeet, Beena, G. M. Kumar, and Sakshi, "Effects of sodium fluoride on some of the hematological parameters of male rabbits," Journal of Advance Researches in Biological Science, vol. 3, no. 1, pp. 58-60, 2011.

[19] A. L. Khandare, P. U. Kumar, and N. Lakshmaiah, "Beneficial effect of tamarind ingestion on fluoride toxicity in dogs," Fluoride, vol. 33, no. 1, pp. 33-38, 2000.

[20] M. H. Karram and T. A. Ibrahim, "Effect of industrial fluorosis on haemogram of camels," Fluoride: Quarterly Reports, vol. 25, no. 1, pp. 23-36, 1992.

[21] I. H. Ersoy, E. G. Alanoglu, B. K. Koroglu et al., "Effect of endemic fluorosis on hematological parameters," Biological Trace Element Research, vol. 138, no. 1-3, pp. 22-27, 2010.

[22] M. H. Trivedi, R. J. Verma, N. P. Sangai, and N. J. Chinoy, "Mitigation by black tea extract of sodium fluoride induced histopathological changes in brain of mice," Fluoride, vol. 45, no. 1, pp. 13-26, 2012.

[23] V. K. Bharti and R. S. Srivastava, "Fluoride-induced oxidative stress in rat's brain and its amelioration by buffalo (Bubalus bubalis) pineal proteins and melatonin," Biological Trace Element Research, vol. 130, no. 2, pp. 131-140, 2009.

[24] Y. Wang, F. Catana, Y. Yang, R. Roderick, and R. B. Van Breemen, "An LC-MS method for analyzing total resveratrol in grape juice, cranberry juice, and in wine," Journal of Agricultural and Food Chemistry, vol. 50, no. 3, pp. 431-435, 2002.

[25] Ü. Sönmez, A. Sönmez, G. Erbil, I. Tekmen, and B. Baykara, "Neuroprotective effects of resveratrol against traumatic brain injury in immature rats," Neuroscience Letters, vol. 420, no. 2, pp. 133-137, 2007.

[26] O. Ates, S. Cayli, E. Altinoz et al., "Neuroprotection by resveratrol against traumatic brain injury in rats," Molecular and Cellular Biochemistry, vol. 294, no. 1-2, pp. 137-144, 2007.

[27] T. Tunali-Akbay, O. Sehirli, F. Ercan, and G. Sener, "Resveratrol protects against methotrexate-induced hepatic injury in rats," Journal of Pharmacy and Pharmaceutical Sciences, vol. 13, no. 2, pp. 303-310, 2010.

[28] S. Dalaklioglu, G. E. Genc, N. H. Aksoy, F. Akcit, and S. Gumuslu, "Resveratrol ameliorates methotrexate-induced hepatotoxicity in rats via inhibition of lipid peroxidation," Human and Experimental Toxicology, vol. 32, no. 6, pp. 662-671, 2013.

[29] C. L. do Amaral, H. D. C. Francescato, T. M. Coimbra et al., "Resveratrol attenuates cisplatin-induced nephrotoxicity in rats," Archives of Toxicology, vol. 82, no. 6, pp. 363-370, 2008.

[30] C. Silan, Ö. Uzun, N. Ü. Çomunoǧlu, S. Gokçen, S. Bedirhan, and M. Cengiz, "Gentamicin-induced nephrotoxicity in rats ameliorated and healing effects of resveratrol," Biological and Pharmaceutical Bulletin, vol. 30, no. 1, pp. 79-83, 2007.

[31] E. Tatlidede, Ö. Şehirli, A. Velioğlu-Öğünç et al., "Resveratrol treatment protects against doxorubicin-induced cardiotoxicity by alleviating oxidative damage," Free Radical Research, vol. 43, no. 3, pp. 195-205, 2009.

[32] G. Eraslan, M. Kanbur, and S. Silici, "Evaluation of propolis effects on some biochemical parameters in rats treated with sodium fluoride," Pesticide Biochemistry and Physiology, vol. 88, no. 3, pp. 273-283, 2007.

[33] E. Eren, M. Özturk, E. F. Mumcu, and D. Canatan, "Fluorosis and its hematological effects," Toxicology and Industrial Health, vol. 21, no. 10, pp. 255-258, 2005. 
[34] M. Mokni, S. Elkahoui, F. Limam, M. Amri, and E. Aouani, "Effect of resveratrol on antioxidant enzyme activities in the brain of healthy rat," Neurochemical Research, vol. 32, no. 6, pp. 981-987, 2007.

[35] M. Mittal and S. J. S. Flora, "Vitamin E supplementation protects oxidative stress during arsenic and fluoride antagonism in male mice," Drug and Chemical Toxicology, vol. 30, no. 3, pp. 263-281, 2007.

[36] S. Arpita and B. Bidyut, "Effect of fluoride toxicity on some clinical, biochemical and physiological aspects of albino rats," International Journal of Research in Chemistry and Environment, vol. 2, no. 1, pp. 160-165, 2012.

[37] A. M. Khan, N. Dubey, R. Raina, G. Singh, and S. A. Beigh, "Toxic effects of deltamethrin and fluoride on hematological parameters in rats," Fluoride, vol. 46, no. 1, pp. 34-38, 2013.

[38] A. Machalinska, J. Nowak, A. Jarema, B. Wiszniewska, and B. Machalinski, "In vivo effects of sodium fluoride on bone marrow transplantation in lethally irradiated mice," Fluoride, vol. 35, no. 2, pp. 81-89, 2002.

[39] A. K. Susheela, “Treatise on fluorosis," Fluoride, vol. 34, no. 3, pp. 181-183, 2001.

[40] M. E. Juan, M. Pilar Vinardell, and J. M. Planas, “The daily oral administration of high doses of trans-resveratrol to rats for 28 days is not harmful," Journal of Nutrition, vol. 132, no. 2, pp. 257260, 2002.

[41] L. E. Donnelly, R. Newton, G. E. Kennedy et al., "Antiinflammatory effects of resveratrol in lung epithelial cells: molecular mechanisms," The American Journal of Physiology: Lung Cellular and Molecular Physiology, vol. 287, no. 4, pp. L774-L783, 2004.

[42] Ş. E. Hişmioğulları, A. A. Hişmioğulları, M. T. Yavuz et al., "The protective effect of resveratrol in experimentally induced nonsterile clean wound inflammation in rats," Kafkas Universitesi Veteriner Fakultesi Dergisi, vol. 19, supplement A, pp. A1-A5, 2013.

[43] M. A. Thrall, G. Weiser, R. Allison, and T. Campbell, "Mammalian hematology: laboratory animals and miscellaneous species," in Veterinary Hematology and Clinical Chemistry, T. W. Campbell, Ed., pp. 225-237, Blackwell Publishing, Malden, Mass, USA, 2012.

[44] H. Bouaziz, S. Ketata, K. Jammoussi et al., "Effects of sodium fluoride on hepatic toxicity in adult mice and their suckling pups," Pesticide Biochemistry and Physiology, vol. 86, no. 3, pp. 124-130, 2006.

[45] X. Xiong, J. Liu, W. He et al., "Dose-effect relationship between drinking water fluoride levels and damage to liver and kidney functions in children," Environmental Research, vol. 103, no. 1, pp. 112-116, 2007.

[46] A. Shashi and S. P. Thapar, "Histopathology of fluoride-induced hepatotoxicity in rabbits," Fluoride, vol. 34, no. 1, pp. 34-42, 2001.

[47] O. Barbier, L. Arreola-Mendoza, and L. M. Del Razo, "Molecular mechanisms of fluoride toxicity," Chemico-Biological Interactions, vol. 188, no. 2, pp. 319-333, 2010.

[48] A. J. Murphy and J. C. Hoover, "Inhibition of the Na,K-ATPase by fluoride. Parallels with its inhibition of the sarcoplasmic reticulum CaATPase," Journal of Biological Chemistry, vol. 267, no. 24, pp. 16995-17000, 1992.

[49] R. E. Anderson, J. W. Kemp, W. S. S. Jee, and D. M. Woodbury, "Effects of cortisol and fluoride on ion-transporting ATPase activities in cultured osteoblastlike cells," In Vitro, vol. 20, no. 11, pp. 847-855, 1984. 

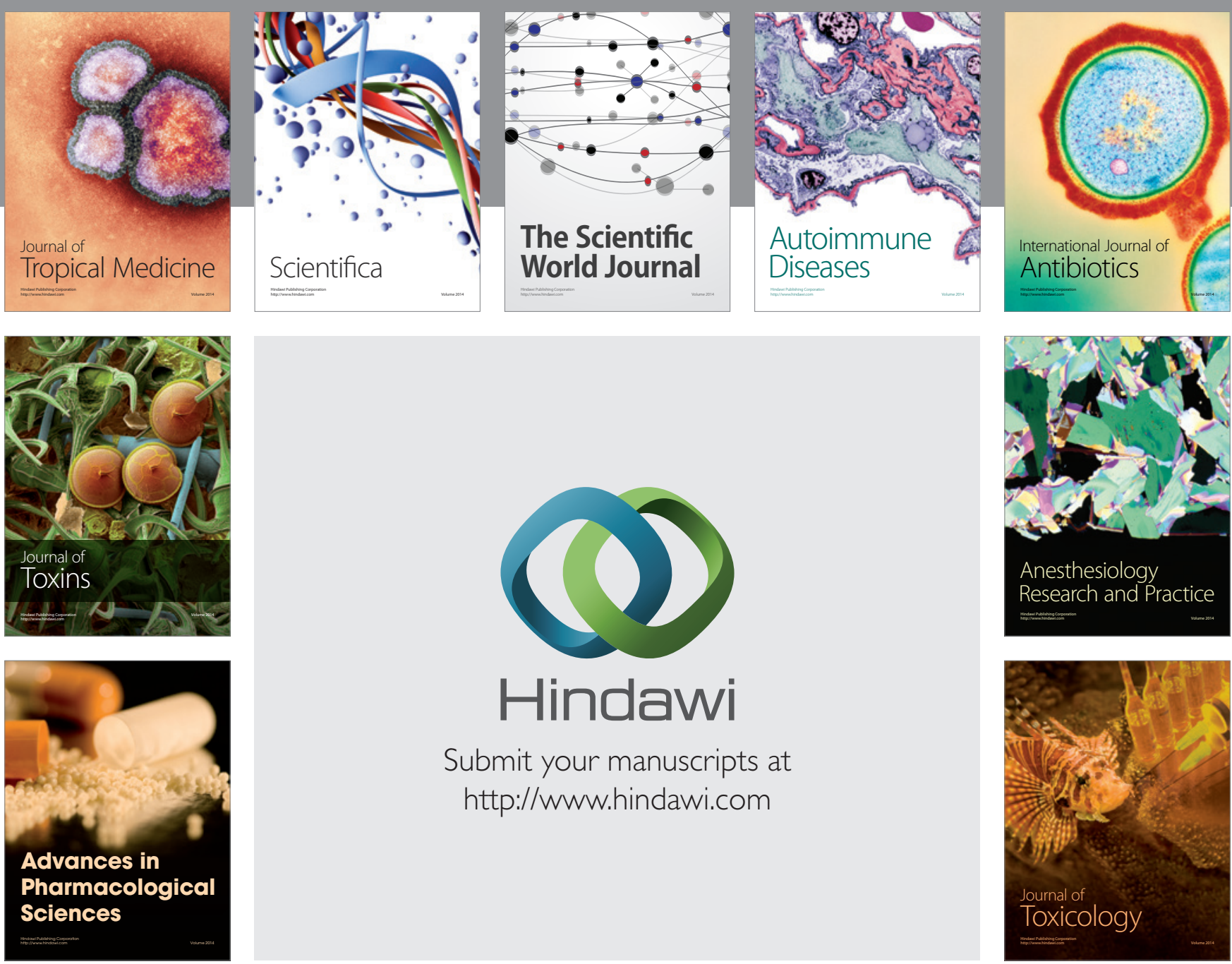

\section{Hindawi}

Submit your manuscripts at

http://www.hindawi.com
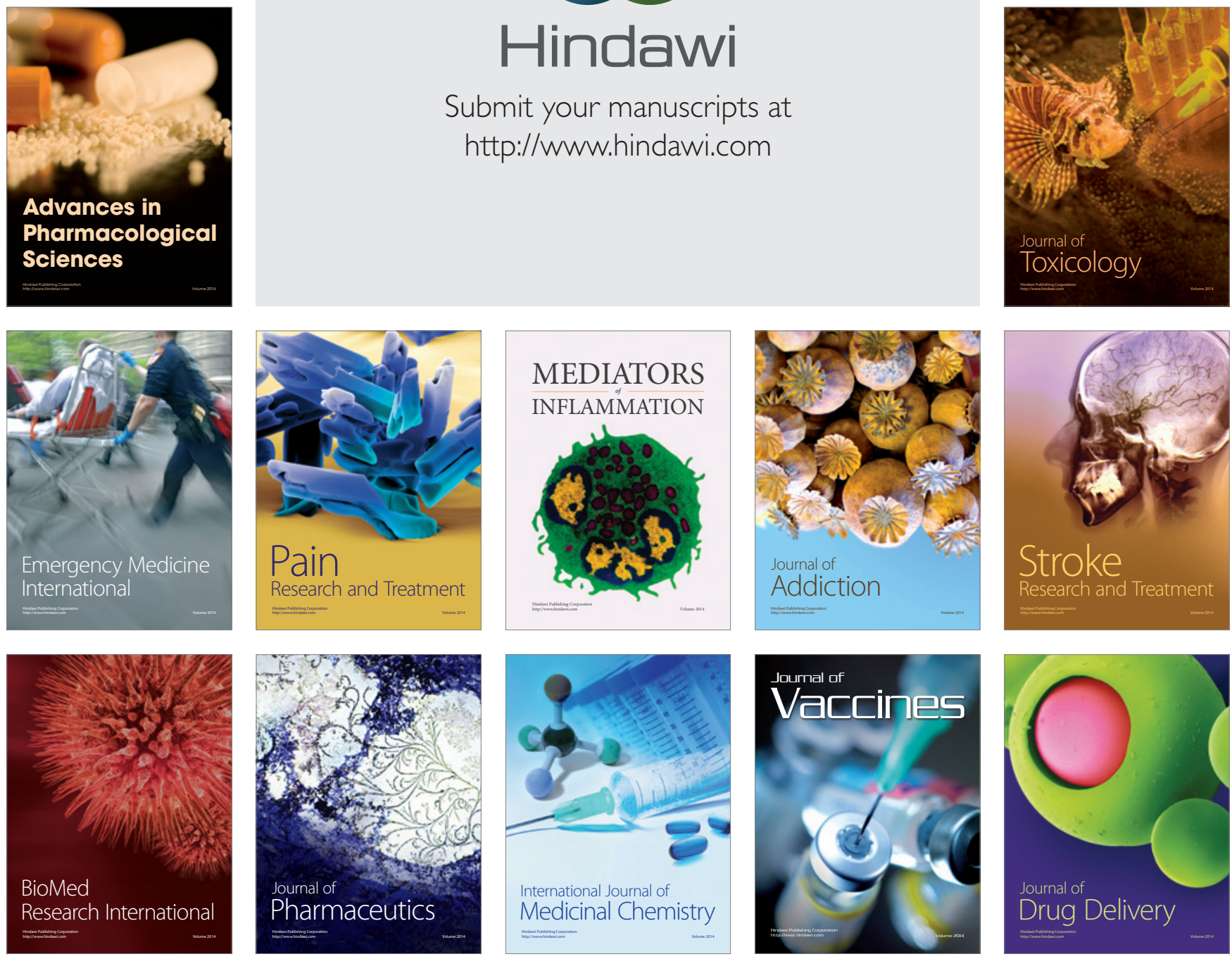